\title{
Hydrogenation over gold catalysts: The interaction of gold with hydrogen
}

\author{
Christiane Kartusch ${ }^{1}$ and Jeroen A van Bokhoven ${ }^{1}$ \\ www.goldbulletin.org
}

\begin{abstract}
Gold is active in various hydrogenation reactions and often shows exceptional high chemoselectivity when multiple functional groups are present. All hydrogenation reactions have in common, that the hydrogen molecules have to adsorb and dissociate before they react. Recent insights in the interaction of gold with hydrogen and simple reactions involving hydrogen are described.
\end{abstract}

\section{Introduction}

Gold is a fascinating element. It has captured the imagination as a valuable object in art and decoration. More recently, it has made a remarkable entrance in the field of catalysis. For many types of reactions, it shows a unique performance. Among the first people who recognized the promise of gold as a catalyst was David Thompson. His review written together with Geoffrey Bond in Catalysis Reviews - Science and Engineering (1) described the early works about gold catalysts and their structure. This review has inspired many researchers throughout the world and contributed to gold being one of the most-studied elements in the field of catalysis. The continued development in catalysis by gold is most apparent by the new review of catalysis by gold, which now appeared in the form of a book co-written by Geoffrey Bond, Catherine Louis, and David Thompson (2). Without the scientific contribution, inspiration and personal engagement and encouragement of David Thompson, the field would not be where it is at the moment. Most of our scientific conversations with David centered around the use of gold in hydrogenation reactions, which is by far less investigated and understood than oxidation reactions. We dedicate this work to him.

Gold catalyzes various hydrogenation reactions such as the hydrogenation of alkenes (3-12), alkadiens (13-18) alkynes (13,19-25), $\alpha, \beta$-unsaturated carbonyl compounds (26-46) and nitro compounds (47-53). In contrast to traditional hydrogenation catalysts such as platinum, palladium or ruthenium, which require modification, it often shows remarkable selectivities when multiple functional groups are present. This makes gold a potential catalyst for the development of new, clean and sustainable production routes with minimal side product formation. Supported gold catalysts were very selective in purifying alkene streams, to prevent poisoning of the polymerization catalysts and ensure pure products (54). On the other hand, over the industrially-used palladium catalysts, 
oligomers are formed, that reduce lifetime (22). Selectivities up to $90 \%$ were obtained over gold for the selective hydrogenation of $\alpha, \beta$-unsaturated carbonyl compounds to the corresponding unsaturated alcohols, which are important intermediates in the production of fine chemicals and pharmaceuticals $(17,41,45-46$,$) . Substituted aromatic amines, also$ important industrial intermediates, were selectively prepared from the corresponding nitro compounds with supported gold catalysts (47), whereas other catalytic systems exhibited major drawbacks such as by-product formation (55-59) and limited reusability (60). Hydrogenation reactions over gold have in common that the hydrogen molecule must be dissociated before it reacts. We aim to describe recent insights into the activation of hydrogen over gold catalysts.

\section{Interaction of gold and hydrogen}

In hydrogenation reactions, chemisorption and dissociation of hydrogen are the essential initial steps. There are only a few studies that investigate the interaction of hydrogen with gold. On Au(110) $(1 \times 2)$ surfaces no hydrogen chemisorption was observed (61). Weak adsorption of a small amount of hydrogen was found on thin, unsintered gold films: At a pressure of $0.3 \mathrm{~Pa}$ and a temperature of $78 \mathrm{~K}$, the hydrogen coverage was less than 0.015 (62). Hydrogen desorbed at around $125 \mathrm{~K}$. The hydrogen desorption activation energy was estimated to be around $12 \mathrm{~kJ} / \mathrm{mol}$. Low coordinated gold atoms on the film surface were suggested to act as adsorption sites. Lin and Vannice (63) detected weak, reversible adsorption of hydrogen on $30 \mathrm{~nm}$ gold particles on $\mathrm{TiO}_{2}$ at 300 and $473 \mathrm{~K}$ leading to a coverage of about $1 \%$ of the total amount of gold. As the hydrogen uptake was found to be greater at $473 \mathrm{~K}$ than at $300 \mathrm{~K}$ it was suggested that the adsorption of hydrogen is an activated process and very likely associated with hydrogen dissociation. The chemisorption of hydrogen on $\mathrm{Al}_{2} \mathrm{O}_{3}$ supported gold particles with a mean cluster size of about 4 $\mathrm{nm}$ was examined by Jia and coworkers (21). They observed that about $14 \%$ of the surface atoms adsorbed hydrogen almost irreversible at $273 \mathrm{~K}$. The hydrogen chemisorption properties of $\mathrm{Au} / \mathrm{Al}_{2} \mathrm{O}_{3}$ and $\mathrm{Au} / \mathrm{SiO}_{2}$ catalysts were investigated by Bus et al. (64) in a temperature range of 298 to $523 \mathrm{~K}$. For the 1 to $1.5 \mathrm{~nm}$ supported gold clusters, $\mathrm{H} / \mathrm{M}$ values (number of adsorbed hydrogen atoms per total number of metal atoms) of at least 0.1 and as high as 0.73 were determined. However only $10-30 \%$ of the total adsorbed hydrogen did not desorb while evacuating for $2 \mathrm{~h}$ at the analysis temperature. The shapes of the hydrogen adsorption isotherms indicated that hydrogen chemisorbs dissociatively. The hydrogen uptake increased or was constant with temperature. This was ascribed to the hydrogen chemisorption on gold being activated. The $\mathrm{Au} / \mathrm{Al}_{2} \mathrm{O}_{3}$ catalyst with the smallest particle size of about $1 \mathrm{~nm}$ exhibited the highest hydrogen uptake per surface atom. At this

\section{Figure 1}
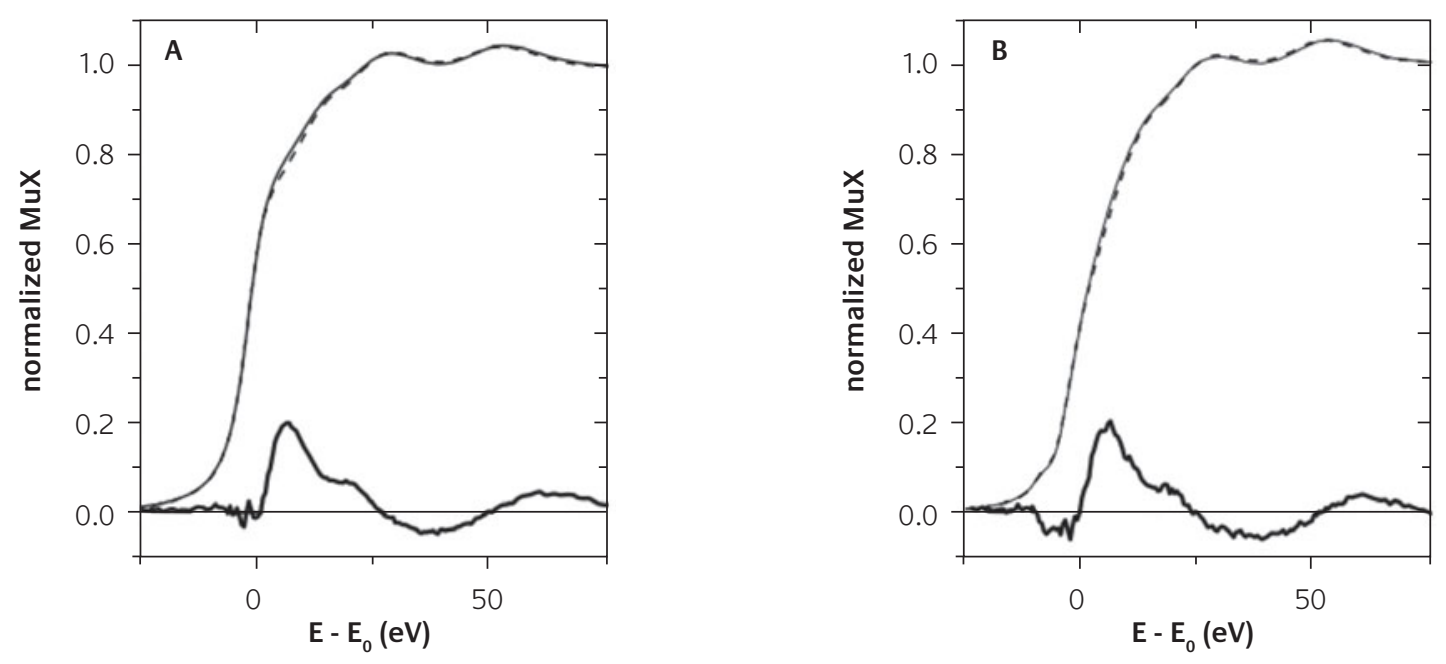

A. $L_{3}$ and B. $L_{2}$ edges of 0.4 wt $\% \mathrm{Au}_{\mathrm{A}} \mathrm{Al}_{2} \mathrm{O}_{3}$ with a mean particle size of $1.3 \mathrm{~nm}$, measured after reduction at $473 \mathrm{~K}$ in hydrogen (solid line) and after removal of hydrogen by evacuation at $473 \mathrm{~K}$ under dynamic vacuum (dashed line) both at $298 \mathrm{~K}$, and their difference multiplied by ten (bold solid line), illustrating the differences in electronic structures after hydrogen adsorption 
size, most of the surface consists of atoms at corner and edge positions. Thus it was proposed that hydrogen atoms only adsorb at edges and corners of the gold particles. The $\mathrm{Au} / \mathrm{H}$ interaction was made visible by X-ray absorption spectroscopy (XAS) (64). Figs. $1 \mathrm{~A}$ and $1 \mathrm{~B}$ show the XANES spectra of the $\mathrm{Au} \mathrm{L}_{3}$ and $\mathrm{L}_{2}$ edge of a $\mathrm{Au} / \mathrm{Al}_{2} \mathrm{O}_{3}$ catalyst with a gold loading of $0.4 \mathrm{wt} \%$ and a mean particle size of 1.3 $\mathrm{nm}$ measured in vacuum and under hydrogen. The spectra represent the empty d-densities of states indicating changes in the gold electronic structure (65). The addition of hydrogen induced small changes in the near-edge structure (XANES). A small white line appeared between 0 and $25 \mathrm{eV}$ over the edge, which was emphasized by the difference spectrum. The white line corresponds to the number of holes in the $\mathrm{d}$ band. When a hydrogen atom adsorbs on a metal surface it interacts with the metal $d$ band. Because the $d$-band is narrow it interacts with the adsorbate by forming bonding and antibonding density of states. Thus both the electron density and the shape of the filled and empty densities of states of the metal d-band change (66). The changes in the spectra in Fig. 1 result from the bonding of hydrogen to the surface gold particles, which alters the electronic structure. The changes in the gold spectra were small compared to those of platinum, because the interaction of hydrogen with gold is weak and the coverage is low.

In summary, hydrogen chemisorbs on gold, though weakly and in small amounts. For both the hydrogen uptake and the strength of adsorption there is a clear particle size effect. With decreasing particle size, increasing amounts of hydrogen are chemisorbed and an increasing fraction is adsorbed strongly. Thus it can be concluded, that the chemisorption is limited to low coordinated corner and edge atoms, which was recently confirmed by theory (50).

\section{$H / D$ exchange over gold}

So far the interaction of gold and hydrogen has been highlighted. Now we take the next step and look at the simplest reaction involving hydrogen, namely the hydrogen-deuterium exchange reaction (Scheme 1). Nieuwenhuys et al. (67) demonstrated that $\mathrm{Au} / \mathrm{Al}_{2} \mathrm{O}_{3}$ catalysts which had a gold particle size smaller than $3 \mathrm{~nm}$ catalyzed the hydrogen-deuterium exchange reaction even at room temperature. Fig. 2 shows the time course of an exchange experiment in a batch reactor at room temperature starting with an equimolar mixture of hydrogen and deuterium over $\mathrm{Au} / \mathrm{Al}_{2} \mathrm{O}_{3}$ with gold particles of about $7 \mathrm{~nm}$. Isotopic

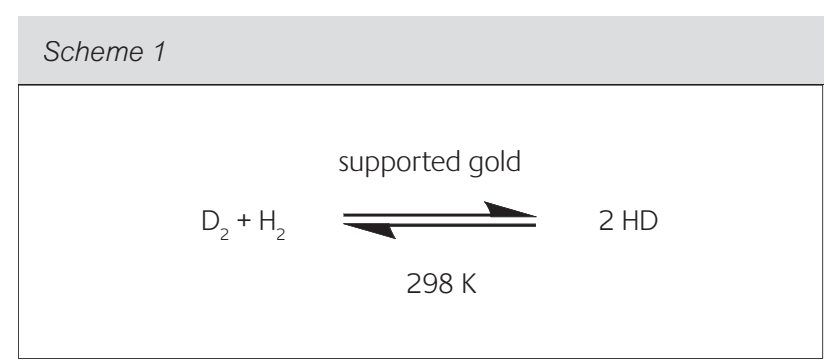

Hydrogen-deuterium exchange reaction

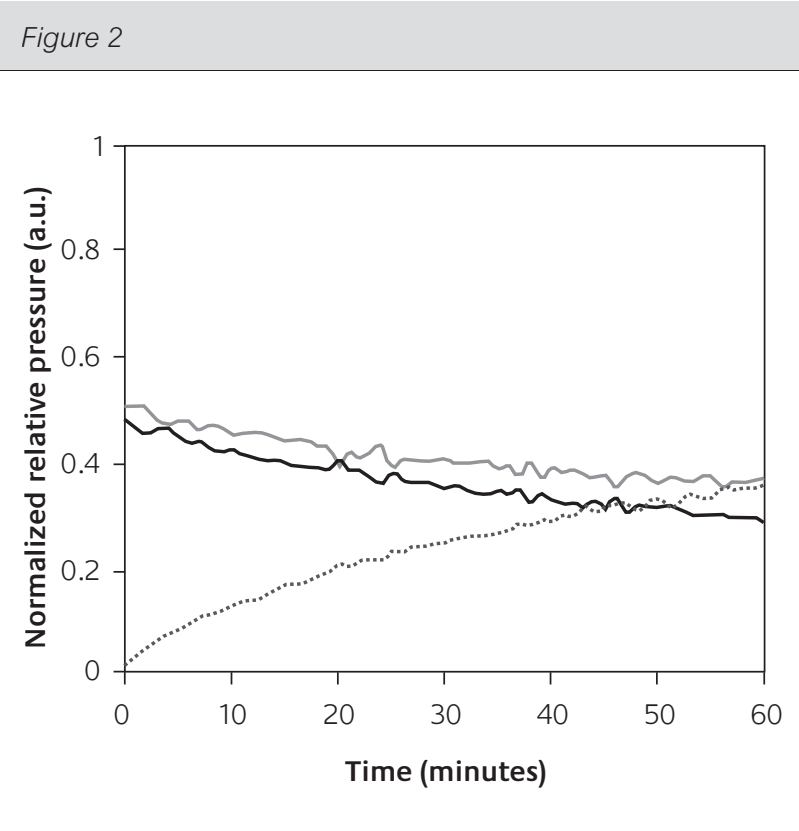

Time course of a hydrogen-deuterium exchange experiment in a batch reactor over $\mathrm{Au} / \mathrm{Al}_{2} \mathrm{O}_{3}$ with gold particles of about $7 \mathrm{~nm}$ at $298 \mathrm{~K}$

equilibration was reached within one hour. Bus et al. (64) also proved that isotope exchange occurred over supported gold catalysts in a flow reactor. For $\mathrm{Au} / \mathrm{Al}_{2} \mathrm{O}_{3}$ catalysts with particle sizes between 1 and $3 \mathrm{~nm}$, the H/D ratio at the reactor exhaust increased with increasing temperature. The temperature dependence of the HD concentration was ascribed to two effects; the dissociation of hydrogen being activated on gold and increase of the rate constant for the recombination of hydrogen and deuterium atoms with increasing temperature. Bond et al. (13) also found a strong particle size effect with the smaller particles being more reactive (vide infra). Recently, Boronat et al. $(68,69)$ investigated the nature of the adsorption sites of hydrogen on $\mathrm{Au} / \mathrm{TiO}_{2}$ catalysts with similar particle sizes of about $3.3 \mathrm{~nm}$. By IR spectroscopy of adsorbed CO, different gold surface 
sites were identified, which could be assigned via DFT calculations. These results were then correlated to those obtained from H/D exchange experiments, and it was confirmed that among the different gold surface sites only low coordinated gold atoms at corners and edges, not directly bonded to oxygen, were active for hydrogen dissociation.

\section{Hydrogenation of simple alkenes}

Another simple reaction involving hydrogen is the hydrogenation of simple alkenes. Only a few studies are found dealing with gold's ability to catalyze this reaction, probably because of its low activity. In an early study, Bond et al. (13) investigated the hydrogenation of ethene with $\mathrm{SiO}_{2}$ supported gold catalysts with gold loadings varying from 0.01 to $5.0 \mathrm{wt} \%$ at $453 \mathrm{~K}$ (Scheme 2). The rate of the ethene hydrogenation per unit weight of gold increased as the gold loading decreased. The least active catalyst was $5 \mathrm{wt} \% \mathrm{Au} / \mathrm{SiO}_{2}$ which contained particles of around $23 \mathrm{~nm}$. This suggests that the fraction of smaller gold particles increased with decreasing gold loading. A close relation between the rate of the ethene hydrogenation and that of hydrogen/ deuterium exchange was observed, reflecting the dependence of both rates on the hydrogen activation on the catalyst surface. $\mathrm{Au} / \mathrm{TiO}_{2}$, prepared via micelle encapsulation which resulted in a mean particle size of $8 \mathrm{~nm}$ catalyzed the hydrogenation of propylene (Scheme 3) with a TOF of $0.04 \mathrm{~s}^{-1}$ (per surface atom) (12). Supported on other oxides such as $\mathrm{ZnO}, \mathrm{ZrO}_{2}$ and $\mathrm{SiO}_{2}$, prepared by the same method gold was not active, which was attributed to the formation of larger clusters. Gold nanoparticles supported on amorphous silica prepared by autoreduction of the gold precursor by the support were active in the liquid phase hydrogenation of cyclohexene at 353 $\mathrm{K}$ and 220 bar hydrogen pressure (10) (Scheme 4). The selectivity towards cyclohexane was 100\%. However, the mean cluster sizes were large, ranging from 10 to $20 \mathrm{~nm}$ with broad size distributions. The smallest particles exhibited the highest catalytic

Scheme 2

$$
\mathrm{H}_{2} \mathrm{C}=\mathrm{CH}_{2} \stackrel{\text { supported gold }}{453 \mathrm{~K}} \mathrm{H}_{3} \mathrm{C}-\mathrm{CH}_{3}
$$

Gas phase hydrogenation of ethene

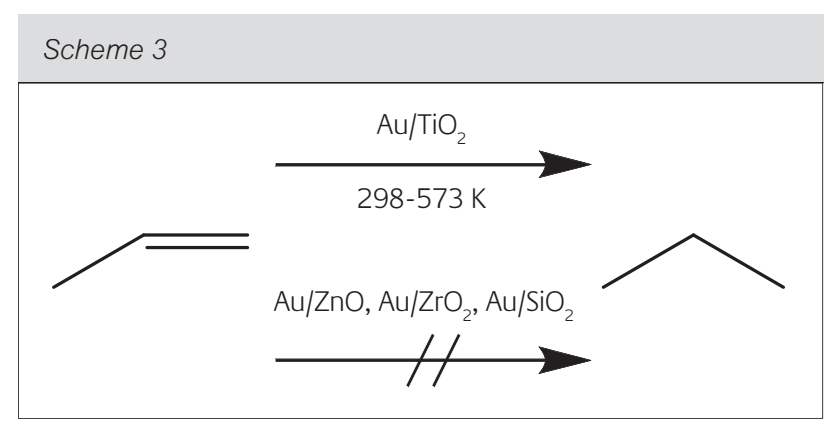

Gas phase hydrogenation of propene

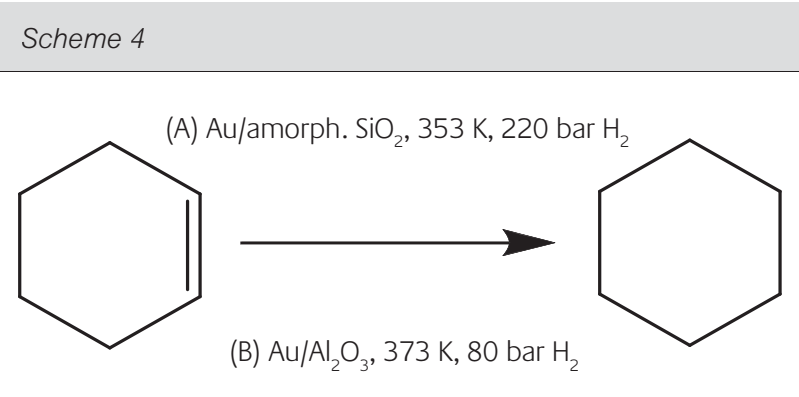

High pressure liquid phase hydrogenation of cyclohexene over supported gold

activity. Bus et al. (45) investigated the activity of $\mathrm{Au} / \mathrm{Al}_{2} \mathrm{O}_{3}$ with a mean particle of $1 \mathrm{~nm}$ in the liquid phase hydrogenation of cyclohexene at $373 \mathrm{~K}$ and a hydrogen pressure of 80 bar (Scheme 4). The TOF per $\mathrm{H}$ adsorbing gold atom was $0.11 \mathrm{~s}^{-1}$, which was two orders of magnitude lower than a platinum catalyst of similar size. The activity of the $\mathrm{Au} / \mathrm{Al}_{2} \mathrm{O}_{3}$ catalyst increased with increasing temperature, hydrogen pressure, and concentration of cyclohexene, suggesting positive order in both reactants. The TOF defined by the number of sites that adsorbs hydrogen was not influenced by the gold particle size. Upon reuse, no deactivation was observed.

In summary, gold is active in gas phase and liquid phase hydrogenation of simple alkenes, although much less than other transition metals such as platinum and palladium. This behavior can be attributed to the weak interaction of gold with both hydrogen and the $\mathrm{C}=\mathrm{C}$ bond.

\section{Conclusion}

Gold activates hydrogen, provided that it is present as nano-sized particles, which are generally stabilized on a support. A strong particle size effect is observed: the smaller the particles are, the more 
hydrogen atoms adsorb on the gold, which has led to the conclusion that it is the edges and corners that adsorb the hydrogen. The role of the support in hydrogenation is much less understood. The adsorption is activated and dissociated, which is shown by the ability of gold catalysts to catalyze the exchange of hydrogen and deuterium and the hydrogenation of simple alkenes. The reactivity is significantly lower than supported metal catalysts that are typically used, which opens the possibility of reaching exceptionally high selectivity when multiple functional groups are present.

\section{Acknowledgement}

We thank the ETH Zurich and the Swiss National Science Foundation for financial support.

\section{About the authors}

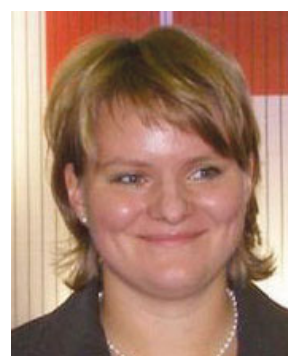

Christiane Kartusch obtained her diploma degree at the Graz University of Technology in 2007. Currently she is a Ph.D. student in the group of Prof. van Bokhoven at the ETH Zurich, Switzerland. Her research focuses on chemo-selective hydrogenation reactions over supported gold catalysts and particularly the investigation of structure performance relations.

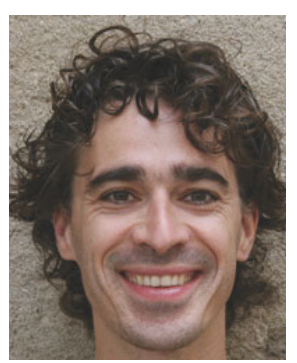

Jeroen van Bokhoven is SNFProfessor in Heterogeneous Catalysis at the Institute for Chemical and Bioengineering since April 1st 2006. He was born December 22nd 1971 in Maassluis, The Netherlands. He finished his studies in 1995 in chemistry at Utrecht University (NL). He obtained his Ph.D. with distinction in 2000 in inorganic chemistry and catalysis. From 1999 until 2002 he was head of the XAS (X-ray absorption spectroscopy) users support group at Utrecht University. In 2002, he moved to the ETH, where he worked as senior researcher in the group of professor Prins. Van Bokhoven works in the field of heterogeneous catalysis and (X-ray) spectroscopy. Goal is the determination of structure-performance relationships, which aid the design and construction of better catalysts for cleaner and more efficient processes. His main interests are heterogeneous catalysts and developing advanced tools in X-ray spectroscopy to study the catalyst structure under catalytic relevant conditions. Their combination provides insight into the structure and function of the catalytically active sites.

\section{References}

1 G.C. Bond, D.T. Thompson, Catal. Rev.-Sci. Eng., 1999, 41, 319

2 G.C. Bond, C. Louis, D.T. Thompson, Catalysis by Gold, (Catalytic Science Series), 2006, 6, Imperial College Press

3 J. Erkelens, C. Kemball, A.K. Galway, Trans. Faraday Soc., 1963, 59, 1181

4 B.J. Wood, H. Wise, J. Catal., 1966, 5, 135

5 R.P. Chambers, M. Boudart, J. Catal., 1966, 5, 517

6 R.S. Yolles, B.J. Wood, H. Wise, J. Catal., 1971, 21, 66

7 G.C. Bond and P.A. Sermon, Gold Bull., 1973, 6, 102

8 P.A. Sermon, G.C. Bond, P.B. Wells, J. Chem. Soc. Faraday Trans. 1, 1979, 75, 385

9 A. Saito, M. Tanimoto, J. Chem. Soc. Chem. Commun., 1988, 12, 832

10 P. Mukherjee, C.R. Patra, A. Gosh, R. Kumar, M. Sastri, Chem. Mater., 2002, 14, 1678

11 J. Guzman, B.C. Gates, Angew. Chem., 2003, 42, 690

12 J. Chou, N.R. Franklin, S.-H. Baeck, T.F. Jaramillo, E.W. McFarland, Catal. Lett., 2004, 95, 107

13 G.C. Bond, P.A. Sermon, G. Webb, D.A. Buchanan, P.B. Wells, J. Chem. Soc. Chem. Commun., 1973, 13, 444b

14 D.A. Buchanan, G. Webb, J. Chem. Soc. Faraday Trans. 1, 1978, 70, 134

15 M. Haruta, Catal. Today,1997, 36, 153

16 N. Bartlett, Gold Bull., 1998, 31, 22

17 M. Okumura, T. Akita, M. Haruta, Catal. Today, 2002, 74, 265

18 A. Hugon, L. Delannoy, C. Louis, Gold Bull., 2008, 41, 127

19 D.V. Sokol'skii, A. Ualikhanova, Russ. J. Phys. Chem., 1982, 56, 633

20 G. Schmid, H. West, J.-O. Malm, J.-O. Bovin, C. Grenthe, Chem. Eur. J., 1996, 2, 1099

21 J. Jia, K. Haraki, J.N. Kondo, K. Domen, K. Tamaru, J. Phys. Chem. B, 2000, 104, 11153

22 T.V. Choudhary, C. Sivadinarayana, A. Dantye, D. Kumar, W.D. Goodman, Catal. Lett., 2003, 86, 1

23 J.A. Lopez-Sanchez, D. Lennon, Appl. Catal. A, 2005, 291, 230

24 Y. Segura, N. Lopez, J. Perez-Ramirez, J. Catal., 2007, 247, 383

25 S.A. Nikolaev, V.V. Smirnov, Gold Bull., 2009, 42, 182

26 C.T.H. Stoddart, C. Kemball, J. Colloid Sci., 1956, 11, 532

27 C. Kemball, C.T.H. Stoddart, Proc. Roy. Soc., 1957, A241, 208

28 M. Haruta, Catal. Today, 1997, 36, 153

29 P. Fordham, M. Besson, P. Gallezot, Stud. Surf. Sci. Catal., 1997, 108, 429

30 J.E. Bailie, G.J. Hutchings, Chem. Commun. 1999, 2151

31 P. Claus, A. Brueckner, C. Mohr, H. Hofmeister, J. Am. Chem. Soc., 2000, 122, 11430

32 C. Mohr, H. Hofmeister, M. Lucas, P. Claus, Chem. Eng. Technol., 2000, 23, 324 
33 J.E. Bailie, H.A. Abdullah, J.A. Anderson, C.H. Rochester, N.V. Richardson, N. Hodge, J.-G. Zhang, A. Burrows, C.J. Kiely, G.J. Hutchings, Phys. Chem. Chem. Phys., 2001, 3, 4113

34 C. Milone, M.L. Tropeano, G. Gulino, G. Neri, R. Ingoglia, S. Galvagno, Chem. Commun., 2002, 8, 868

35 S. Schimpf, M. Lucas, C. Mohr, U. Rodemerck, A. Bruckner, J. Radnik, H. Hofmeister, P. Claus, Catal. Today, 2002, 72, 63

36 C. Milone, R. Ingoglia, M.L. Tropeano, G. Neri, S. Galvagno, Chem. Commun., 2003, 7, 868

37 C. Mohr, H. Hofmeister, J. Radnik, P. Claus, J. Am. Chem. Soc., 2003, 125, 1905

38 C. Mohr, H. Hofmeister, P. Claus, J. Catal., 2003, 213, 86

39 J. Radnik, C. Mohr, P. Claus, Phys. Chem. Chem. Phys., 2003, 5, 172

40 C. Milone, R. Ingoglia, A. Pistone, G. Neri, F. Frusteri, S. Galvagno, J. Catal., 2004, 222, 348

41 R. Zanella, C. Louis, S. Giorgio, R. Touroude, J. Catal., 2004, 223, 328

42 P. Claus, Appl. Catal. A: General, 2005, 291, 222

43 C. Milone, R. Ingoglia, L. Schipilliti, C. Crisafulli, G. Neri, S. Galvagno, J. Catal., 2005, 236, 80

44 B. Campo, M. Volpe, S. Ivanova, R. Touroude, J. Catal., 2006, 242, 162

45 E. Bus, R. Prins, J.A. van Bokhoven, Catal. Commun., 2007, 8, 1397

46 C. Milone, C. Crisafulli, R. Invoglia, L. Schipilliti, S. Galgano, Catal. Today, 2007, 122, 341

47 A. Corma, P. Serna, Science, 2006, 313, 332

48 A. Corma, P. Concepción, P. Serna, Angew. Chem., Int. Ed., 2007, 46, 7266

49 A. Corma, P. Serna, H. García, J. Am. Chem. Soc., 2007, 129, 6358
50 M. Boronat, P. Concepción, A. Corma, S. Gonzàlez, F. Illas, P. Serna, J. Am. Chem. Soc., 2007, 129, 16230

51 A. Grirrane, A. Corma, H. García, Science, 2008, 322, 1661

52 F. Cárdenas-Lizana, S. Gómez-Quero, N. Perret, M.A. Keane, Gold Bull., 2009, 42, 124

53 L.L. Santos, P. Serna, A. Corma, Chem. Eur. J., 2009, 15, 8196

54 M.L. Derrien, Stud. Surf. Sci. Catal., 1986, 27, 613

55 M. Suchy, P. Winternitz, M. Zeller, World (WO) Patent 91/00278, 1991

56 F. Kovar, F.E. Armond, U.S. Patent 3,975,444,1976

57 J. Butera, J. Bagli, WO Patent 91/09023, 1991

58 A. Burawoy, J.P. Critchley, Tetrahedron, 1959, 5, 340

59 R. Braden, H. Knupfer, S. Hartung, U.S. Patents 4,002,673 and $4,051,177,1977$

60 M.A. Narendra, O.P. Shivanand, D.R. Madhukar, WO Patent, 2005.070.869, 2005

61 A.G. Sault, R.J. Madix, C.T. Campell, Surf. Sci., 1986, 169, 347

62 L. Stobinsky, L. Zommer, R. Dus, Appl. Surf. Sci., 1999, 141, 319

63 S. Lin, M.A.T. Vannice, Catal. Lett., 1991, 10, 47

64 E. Bus, J.T. Miller, J.A. van Bokhoven, J. Phys. Chem. B, 2005, 109, 14581

65 F.W. Lytle, J. Catal., 1976, 43, 376

66 B. Hammer, J.K. Norskov, Nature, 1995, 376, 238

67 A.C. Gluhoi, H.S. Vreeburg, J.W. Bakker, B.E. Nieuwenhuys, Appl. Catal. A: General, 2005, 291, 145

68 M. Boronat, P. Conception, A. Corma, J. Phys. Chem C, 2009, 113, 16772

69 M. Boronat, F. Illas, A. Corma, J. Phys. Chem. A, 2009, 113 3750 